Review Article

\title{
miR-19 Is a Potential Clinical Biomarker for Gastrointestinal Malignancy: A Systematic Review and Meta-analysis
}

\author{
Xiaoxu Song $\mathbb{D},{ }^{1}$ Wenyi Li, ${ }^{2}$ Peng Shen, ${ }^{1}$ Bing Bai, ${ }^{1}$ and Lin-Lin Cao $\mathbb{D}^{2}$ \\ ${ }^{1}$ Department of Clinical Laboratory, Wu'an First People's Hospital, Handan, China \\ ${ }^{2}$ Department of Clinical Laboratory, Peking University People's Hospital, Beijing, China \\ Correspondence should be addressed to Xiaoxu Song; hengxingsong2008@163.com
}

Received 20 February 2020; Revised 15 June 2020; Accepted 26 June 2020; Published 10 September 2020

Academic Editor: Xin-yuan Guan

Copyright (C) 2020 Xiaoxu Song et al. This is an open access article distributed under the Creative Commons Attribution License, which permits unrestricted use, distribution, and reproduction in any medium, provided the original work is properly cited.

Objectives. To assess the expression and clinical value of miR-19 in gastrointestinal malignancy. Setting. Embase, Web of Science, PubMed, and other databases were retrieved to screen out relevant studies until December 31, 2019. Participants. Gastrointestinal cancer patients with the description of miR-19 expression, as well as the correlation between miR-19 and clinicopathological characteristics or prognosis. Main Outcome Measures. Pooled odds ratio (OR) or hazard ratio (HR) with 95\% confidence interval (CI) was obtained to determine miR-19 expression in gastrointestinal malignancy and the association between miR-19 and patients' clinical characteristics and survival. Results. Thirty-seven studies were included in this study. miR-19 levels in gastrointestinal malignancy, especially in hepatocellular $(\mathrm{OR}=4.88,95 \% \mathrm{CI}=2.38-9.99)$, colorectal $(\mathrm{OR}=4.81,95 \% \mathrm{CI}=2.38$ 9.72), and pancreatic $(\mathrm{OR}=5.12,95 \% \mathrm{CI}=2.43-10.78)$ cancers, were significantly overexpressed, and miR-19 was tightly related to some clinicopathological characteristics, such as lymph node metastasis $(\mathrm{OR}=1.74,95 \% \mathrm{CI}=1.05-2.86)$. Although gastrointestinal cancer patients with low and high miR-19 expression had comparable OS (overall survival) and DFS (diseasefree survival), subgroup analyses showed that patients with high miR-19 presented better DFS than those with low miR-19 in liver cancer $(\mathrm{HR}=0.46,95 \% \mathrm{CI}=0.30-0.71)$. Conclusions. miR-19 might be a potential progression and prognostic biomarker for gastrointestinal malignancy.

\section{Background}

Gastrointestinal malignancy is extremely harmful to humans, including gastric, pancreatic, esophageal, liver, and colorectal cancers and other types of cancer in the digestive tract. Their morbidity and mortality rates are really high, especially in less-developed countries [1]. Although great progress has been achieved in early diagnosis and therapy during the past few decades, the overall survival (OS) for gastrointestinal malignancy is still unsatisfactory [2]. Therefore, it is essential to identify novel biomarkers for patients' early diagnosis and better prognosis.

MicroRNAs (miRNAs) are a kind of small noncoding RNA, which can modulate gene expression by cleaving tar- geted messenger RNA (mRNA) or repressing translation [3]. A number of studies have reported that miRNAs show the potential to be novel cancer biomarkers for early detection of cancer [4-6]. MicroRNA-19 (miR-19), which is one member of the large miRNA family, has been demonstrated to be tightly correlated with gastrointestinal malignancy [7-10]. However, the exact role of miR-19 in gastrointestinal malignancy is still unclear.

In the present study, a systematic review and metaanalysis was carried out to assess the association of miR-19 with gastrointestinal cancers. At first, miR-19 expression in gastrointestinal cancer tissue and normal tissue was compared, and then, the correlation of the miR-19 level with several clinical characteristics was evaluated. In addition, the 
role of miR-19 in prognosis for patients with gastrointestinal cancers was also determined.

\section{Methods}

2.1. Search Strategy and Inclusion Criteria. Original researches reporting the association of miR-19 with the progression or prognosis of gastrointestinal cancers were retrieved in Embase, Web of Science, PubMed, and other databases until December 31, 2019. No language restriction was used. We selected studies according to the following keywords: "miR-19", “microRNA-19”, or "miRNA-19” for miR19; "colorectal carcinoma" or "colorectal cancer" for colorectal cancer; "esophageal cancer" or "esophagus neoplasm" for esophageal cancer; "gastric neoplasm", "gastric cancer", or "stomach cancer" for gastric cancer; "liver cancer", "hepatocellular carcinoma", or "hepatocellular cancer" for liver cancer; and "pancreatic neoplasm" or "pancreatic cancer" for pancreatic cancer.

Then, full texts of the relevant studies were evaluated deeply. The inclusion criteria were the following: (1) the expression level of miR-19 was detected by PCR, (2) the clinicopathological parameters or patient survival of gastrointestinal cancers were investigated, and (3) the association of miR-19 with clinicopathological parameters or patient survival was assessed. Studies were excluded if (1) they were not original articles, such as letters, case reports, or reviews; (2) they were focusing on cancer cells or animal models, rather than human samples; or (3) the full texts were not available. Two authors, Xiaoxu Song and Lin-Lin Cao, performed the evaluations independently, and disagreement was settled according to the original article.

2.2. Data Extraction. Data were extracted by Xiaoxu Song and Wenyi Li independently. The extracted information included the first author's name, country, publication year, age and number of patients, the method of miR-19 detection, cut-off point, histology, clinical stage, and survival. If the cutoff point of miR-19 was not described in the studies, the mean value was used as the cut-off point. If there was only a histogram and no original data for miR-19 expression were provided, Engauge Digitizer 4.1 was applied to extract the needed data. In addition, Engauge Digitizer 4.1 was also used for the survival data if there were only Kaplan-Meier curves in the included studies [11].

2.3. Quality Assessment. The quality evaluation of the retrieved studies was completed by Xiaoxu Song and Wenyi Li independently based on the Newcastle-Ottawa Scale (NOS), which includes three parts: sample selection, comparability, and exposure ascertainment.

2.4. Statistical Analysis. All analyses were carried out with Review Manager 5.3 (Cochrane Collaboration, Oxford, UK). The odds ratio (OR) with 95\% confidence interval (CI) was calculated to compare miR-19 levels between the tumor group and the control group and to analyze the correlation between miR-19 and clinicopathologic characters of gastrointestinal cancers. The association of miR-19 levels with patient prognosis was determined using

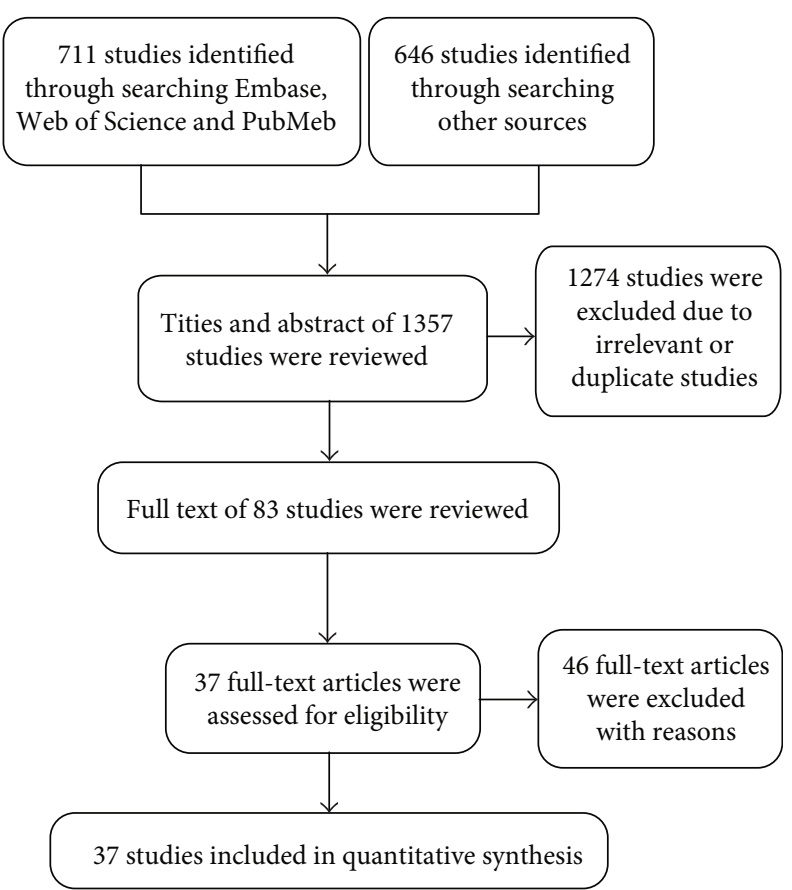

Figure 1: Methodological flow chart of study selection.

the hazard ratio (HR) with $95 \%$ confidence interval (CI). The model of random effect was used if $I^{2}>50 \%$; otherwise, the model of fixed effect was applied $\left(I^{2} \leq 50 \%\right)$. $P<$ 0.05 was statistically significant. The funnel plot was depicted to determine publication bias.

2.5. Patient and Public Involvement. There is no patient involved.

\section{Results}

3.1. Description of the Included Cohorts. In this analysis, 711 studies were identified through searching Embase, PubMed, and Web of Science, and 646 studies were identified in other databases. In total, 1357 studies were found initially (Figure 1). Then, 1274 studies were excluded due to their irrelevance or duplication after checking their titles and abstracts. The remaining 83 studies were read carefully in full text, and 46 were excluded as well because of the following two reasons: (1) there was no data of human samples but only cell lines or animal models or (2) relevant data was not available. Finally, 37 studies [7, 9, 10, 12-45] were included in this analysis, including 12 studies focusing on colorectal cancer, 11 studies focusing on gastric cancer, 8 studies focusing on liver cancer, 2 study focusing on esophageal cancer, and 4 studies focusing on pancreatic cancer. Some characteristics and results of these studies are described in Table 1. Totally, 3472 cases were included in this analysis. All these studies used real-time polymerase chain reaction (RT-PCR) for miR-19 detection. NOS evaluation results suggested high quality of all the studies (Table 2).

3.2. miR-19 Levels in Gastrointestinal Cancers Were Higher than Those in Noncancerous Controls. Most of the included 
TABLE 1: Main characteristics and results of the included studies.

\begin{tabular}{|c|c|c|c|c|c|c|c|c|c|c|}
\hline Study & Year & $\begin{array}{l}\text { Country } \\
\text { or area }\end{array}$ & $\begin{array}{l}\text { Sample } \\
\text { number }\end{array}$ & Age & $\begin{array}{c}\text { Detection } \\
\text { method }\end{array}$ & Cut-off point & Histology & Stage & $\begin{array}{c}\text { Follow-up } \\
\text { period (month) }\end{array}$ & Survival \\
\hline Yamada & 2015 & USA & 48 & NR & RT-PCR & $>$ median & CRC & NR & NR & NR \\
\hline Kahlert & 2011 & Germany & 29 & NR & RT-PCR & NR & CRC & NR & 60 & $\begin{array}{l}\text { OS, } \\
\text { RFS }\end{array}$ \\
\hline Cellura & 2015 & UK & 10 & NR & RT-PCR & $\geq$ median & CRC & NR & NR & NR \\
\hline Huang & 2015 & China & 275 & $\begin{array}{c}60 \\
\text { (mean) }\end{array}$ & RT-PCR & $\geq 0.22$ & CRC & I-IV & NR & OS \\
\hline Jiang & 2017 & China & 211 & $\begin{array}{c}65 \\
\text { (mean) }\end{array}$ & RT-PCR & $>$ median & CRC & I-IV & 59 (median) & $\begin{array}{l}\text { OS, } \\
\text { DFS }\end{array}$ \\
\hline Mastumura & 2015 & Japan & 209 & $\begin{array}{c}65 \\
\text { (mean) }\end{array}$ & RT-PCR & NR & CRC & I-IV & 60 & $\begin{array}{l}\text { OS, } \\
\text { DFS }\end{array}$ \\
\hline Cruz-Gil & 2018 & Spain & 126 & NR & RT-PCR & NR & CRC & II-III & NR & DFS \\
\hline Koga & 2010 & Japan & 62 & $\begin{array}{c}60 \\
\text { (median) }\end{array}$ & RT-PCR & $>$ median & CRC & NR & NR & NR \\
\hline Zhu & 2017 & China & 166 & $\begin{array}{c}60 \\
(\text { mean})\end{array}$ & RT-PCR & $>$ median & CRC & I-IV & NR & NR \\
\hline Zhang & 2018 & China & 56 & $\begin{array}{c}60 \\
\text { (mean) }\end{array}$ & RT-PCR & $>$ median & CRC & I-IV & 80 & OS \\
\hline Yin & 2019 & China & 30 & $\begin{array}{c}50 \\
\text { (mean) }\end{array}$ & RT-PCR & $>$ median & CRC & I-IV & NR & NR \\
\hline Marcuello & 2019 & Spain & 59 & $\begin{array}{c}62 \\
\text { (mean) }\end{array}$ & RT-PCR & NR & CRC & I-IV & NR & NR \\
\hline Guo & 2014 & China & 51 & $\begin{array}{c}50 \\
(\text { mean })\end{array}$ & RT-PCR & $>$ median & HCC & I-IV & 60 & OS \\
\hline Han & 2012 & China & 105 & $\begin{array}{c}56.5 \\
\text { (mean) }\end{array}$ & RT-PCR & NR & HCC & I-IV & 80 & $\begin{array}{l}\text { OS, } \\
\text { DFS }\end{array}$ \\
\hline $\mathrm{Hu}$ & 2018 & China & 20 & NR & RT-PCR & $>$ median & HCC & NR & NR & NR \\
\hline Hung & 2015 & Taiwan & 81 & $\begin{array}{c}60 \\
\text { (mean) }\end{array}$ & RT-PCR & $\geq$ median & HCC & II-IV & 37 (mean) & $\begin{array}{l}\text { OS, } \\
\text { DFS }\end{array}$ \\
\hline $\mathrm{Yu}$ & 2016 & China & 43 & NR & RT-PCR & $\geq$ median & HCC & NR & NR & NR \\
\hline Zhang & 2015 & China & 130 & $\begin{array}{c}50 \\
\text { (mean) }\end{array}$ & RT-PCR & $\geq$ median & HCC & I-IV & 60 & $\begin{array}{l}\text { OS, } \\
\text { DFS }\end{array}$ \\
\hline Zhu & 2010 & China & 95 & $\begin{array}{c}50 \\
(\text { mean })\end{array}$ & RT-PCR & Relative expression $>1.04$ & $\mathrm{HCC}$ & I-III & 62.6 (mean) & OS \\
\hline Jiang & 2018 & China & 22 & NR & RT-PCR & $\geq$ median & HCC & NR & NR & NR \\
\hline Cai & 2016 & China & 60 & NR & RT-PCR & $>$ median & GC & NR & NR & NR \\
\hline $\mathrm{Li}$ & 2014 & China & 30 & $\begin{array}{c}50 \\
(\text { mean })\end{array}$ & RT-PCR & NR & GC & I-IV & NR & NR \\
\hline $\begin{array}{l}\text { Ibarrola- } \\
\text { Villava }\end{array}$ & 2015 & Spain & 45 & NR & RT-PCR & $\geq$ median & GC & NR & NR & NR \\
\hline Wang & 2016 & China & 90 & $\begin{array}{c}65 \\
\text { (mean) }\end{array}$ & RT-PCR & $>$ median & GC & I-IV & 60 & $\begin{array}{l}\text { OS, } \\
\text { DFS }\end{array}$ \\
\hline Wang & 2017 & China & 120 & 60 & RT-PCR & Fold change $>1.5$ & GC & I-IV & NR & NR \\
\hline $\mathrm{Wu}$ & 2014 & China & 141 & $\begin{array}{c}60 \\
(\text { mean })\end{array}$ & RT-PCR & $\geq$ median & GC & I-IV & 70 & OS \\
\hline Zhu & 2018 & China & 180 & $\begin{array}{c}60 \\
\text { (mean) }\end{array}$ & RT-PCR & Score $\geq 2$ & GC & I-IV & NR & NR \\
\hline Liu & 2018 & China & 80 & $\begin{array}{c}65.1 \\
(\text { mean })\end{array}$ & RT-PCR & 2.072 & GC & I-IV & NR & NR \\
\hline $\mathrm{Li}$ & 2018 & China & 42 & NR & RT-PCR & $\geq$ median & GC & NR & NR & $\mathrm{NR}$ \\
\hline Zhu & 2019 & China & 40 & NR & RT-PCR & $\geq$ median & GC & NR & NR & NR \\
\hline Peng & 2018 & China & 333 & $\begin{array}{c}59.42 \\
(\text { mean) }\end{array}$ & RT-PCR & $\geq$ median & GC & I-IV & 60 & OS, PFS \\
\hline $\mathrm{Xu}$ & 2014 & China & 105 & $\begin{array}{c}55 \\
\text { (mean) }\end{array}$ & RT-PCR & $\mathrm{T} / \mathrm{N} \geq 2$ & $\mathrm{EC}$ & I-IV & 34.5 (median) & OS, PFS \\
\hline Bai & 2017 & China & 89 & $\begin{array}{c}58 \\
\text { (mean) }\end{array}$ & RT-PCR & $\geq 0.2909$ & $\mathrm{EC}$ & I-IV & NR & NR \\
\hline
\end{tabular}


TABLe 1: Continued.

\begin{tabular}{|c|c|c|c|c|c|c|c|c|c|c|}
\hline Study & Year & $\begin{array}{c}\text { Country } \\
\text { or area }\end{array}$ & $\begin{array}{l}\text { Sample } \\
\text { number }\end{array}$ & Age & $\begin{array}{l}\text { Detection } \\
\text { method }\end{array}$ & Cut-off point & Histology & Stage & $\begin{array}{c}\text { Follow-up } \\
\text { period (month) }\end{array}$ & Survival \\
\hline Tan & 2015 & China & 58 & NR & RT-PCR & $\geq$ median & $\mathrm{PC}$ & NR & $\mathrm{NR}$ & OS \\
\hline $\mathrm{Qu}$ & 2014 & China & 39 & $\begin{array}{c}65 \\
\text { (mean) }\end{array}$ & RT-PCR & NR & PC & I-IV & NR & NR \\
\hline Zou & 2019 & China & 129 & $\begin{array}{c}60 \\
(\text { mean })\end{array}$ & RT-PCR & $>$ median & PC & I-IV & NR & OS \\
\hline $\mathrm{Hu}$ & 2016 & China & 63 & NR & RT-PCR & $\geq$ median & $\mathrm{PC}$ & NR & NR & NR \\
\hline
\end{tabular}

Abbreviations: NR: not reported; RT-PCR: real-time polymerase chain reaction; T/N: tumor/normal; CRC: colorectal cancer; EC: esophagus cancer; GC: gastric cancer; PC: pancreatic cancer; LC: liver cancer; OS: overall survival; DFS: disease-free survival; RFS: recurrence-free survival; PFS: progression-free survival.

TABle 2: Newcastle-Ottawa Scale for each included study.

\begin{tabular}{|c|c|c|c|c|}
\hline Study & Selection & Comparability & Exposure & Total quality score \\
\hline Yamada, 2015 & 3 & 1 & 3 & 7 \\
\hline Kahlert, 2011 & 3 & 2 & 3 & 8 \\
\hline Cellura, 2015 & 3 & 0 & 3 & 6 \\
\hline Huang, 2015 & 3 & 2 & 3 & 8 \\
\hline Jiang, 2017 & 3 & 2 & 3 & 8 \\
\hline Mastumura, 2015 & 4 & 2 & 3 & 9 \\
\hline Cruz-Gil, 2018 & 3 & 1 & 3 & 7 \\
\hline Koga, 2010 & 3 & 1 & 3 & 7 \\
\hline Zhu, 2017 & 3 & 2 & 3 & 8 \\
\hline Zhang, 2018 & 3 & 3 & 3 & 9 \\
\hline Yin, 2019 & 3 & 3 & 2 & 8 \\
\hline Marcuello, 2019 & 3 & 3 & 3 & 9 \\
\hline Guo, 2014 & 3 & 2 & 2 & 7 \\
\hline Han, 2012 & 3 & 2 & 3 & 8 \\
\hline $\mathrm{Hu}, 2018$ & 3 & 0 & 3 & 6 \\
\hline Hung, 2015 & 3 & 2 & 3 & 8 \\
\hline Yu, 2016 & 3 & 1 & 3 & 7 \\
\hline Zhang, 2015 & 3 & 2 & 3 & 8 \\
\hline Zhu, 2010 & 3 & 2 & 2 & 7 \\
\hline Jiang, 2018 & 3 & 2 & 2 & 7 \\
\hline Cai, 2016 & 3 & 2 & 3 & 8 \\
\hline $\mathrm{Li}, 2014$ & 4 & 2 & 3 & 9 \\
\hline Ibarrola-Villava, 2015 & 3 & 2 & 3 & 8 \\
\hline Wang, 2016 & 4 & 2 & 3 & 9 \\
\hline Wang, 2017 & 4 & 2 & 3 & 9 \\
\hline Wu, 2014 & 3 & 2 & 3 & 8 \\
\hline Zhu, 2018 & 3 & 2 & 3 & 8 \\
\hline Liu, 2018 & 3 & 3 & 3 & 9 \\
\hline $\mathrm{Li}, 2018$ & 3 & 2 & 2 & 7 \\
\hline Zhu, 2019 & 2 & 3 & 2 & 7 \\
\hline Peng, 2018 & 3 & 3 & 3 & 9 \\
\hline $\mathrm{Xu}, 2014$ & 4 & 2 & 3 & 9 \\
\hline Bai, 2017 & 3 & 2 & 3 & 8 \\
\hline Tan, 2015 & 3 & 0 & 3 & 6 \\
\hline Qu, 2014 & 2 & 1 & 3 & 6 \\
\hline Zou, 2019 & 3 & 2 & 3 & 8 \\
\hline $\mathrm{Hu}, 2016$ & 3 & 1 & 3 & 7 \\
\hline
\end{tabular}




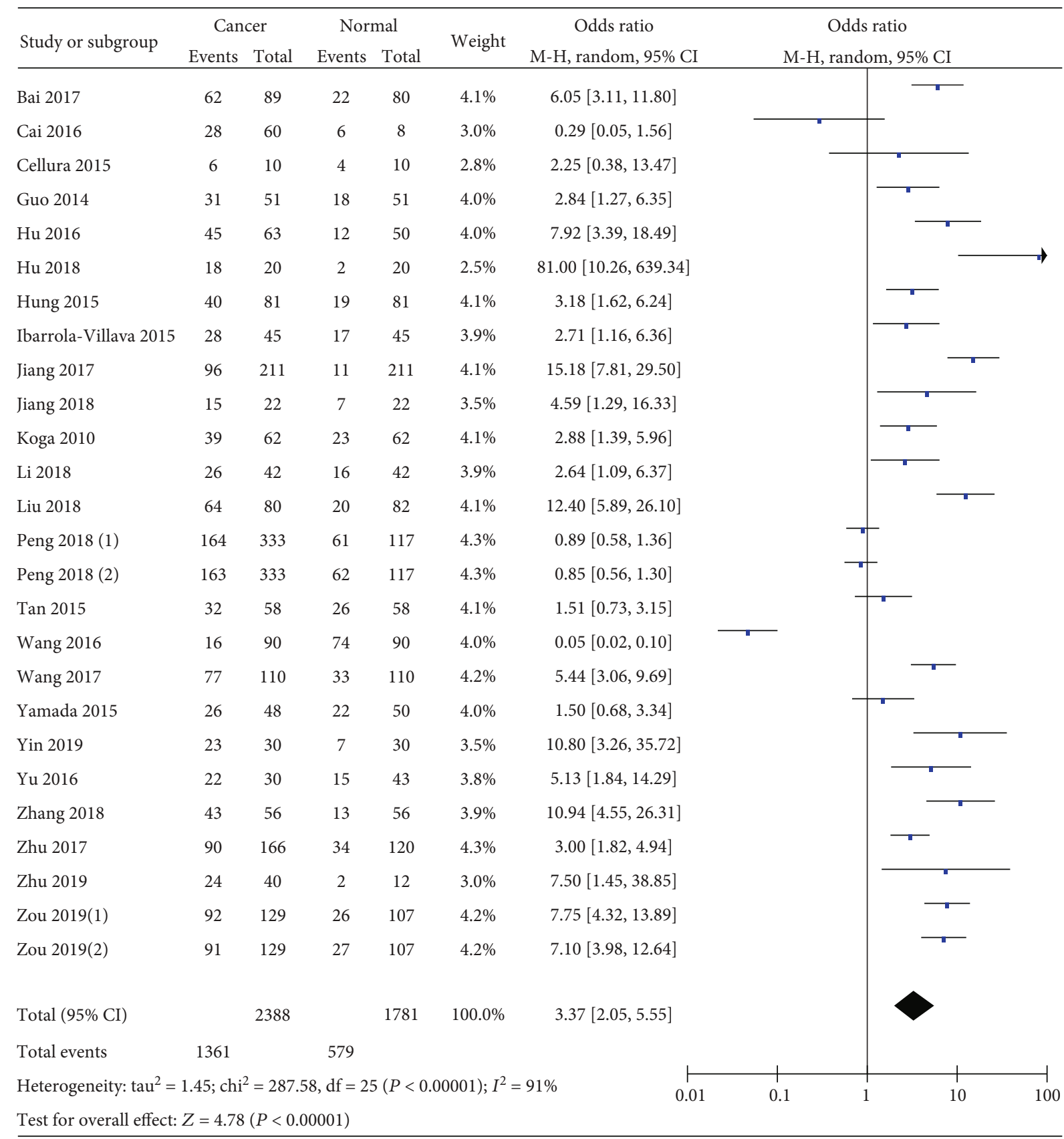

FIGURE 2: Forest plot of odds ratio (OR). Relative miR-19 abundance of overall gastrointestinal malignancy in comparison to noncancerous controls.

studies have compared miR-19 levels between gastrointestinal cancers and noncancerous controls, including 7 studies focusing on colorectal cancer, 8 studies focusing on gastric cancer, 5 studies focusing on liver cancer, 3 studies focusing on pancreatic cancer, and only 1 study focusing on esophageal cancer. The result is shown in Figure $2(\mathrm{OR}=3.37$, $95 \% \mathrm{CI}=2.05-5.55)$, suggesting that miR-19 levels in gastrointestinal malignancy were higher than those in controls.

Then, we carried out subgroup analysis according to different cancers. As shown in Figure 3(a), miR-19 levels in liver cancer were higher than those in the control group $(\mathrm{OR}=4.88$, $95 \% \mathrm{CI}=2.38-9.99$ ). Similar results were found in colorectal cancer $(\mathrm{OR}=4.81,95 \% \mathrm{CI}=2.38-9.72)$ and pancreatic cancer $(\mathrm{OR}=5.12,95 \% \mathrm{CI}=2.43-10.78)$ (Figures $3(\mathrm{~b})$ and $3(d))$. However, no significant distinction existed between gastric cancer and noncancerous group (Figure 3(c)). There was only one study focusing on esophageal cancer. Taken together, these data indicate that miR-19 levels in gastrointestinal cancers, especially colorectal, liver, and pancreatic cancers, were higher than those in noncancerous controls.

3.3. Association of miR-19 Expression with the Clinical Characteristics of Patients with Gastrointestinal Malignancy. Next, we determined the correlation between miR-19 and 


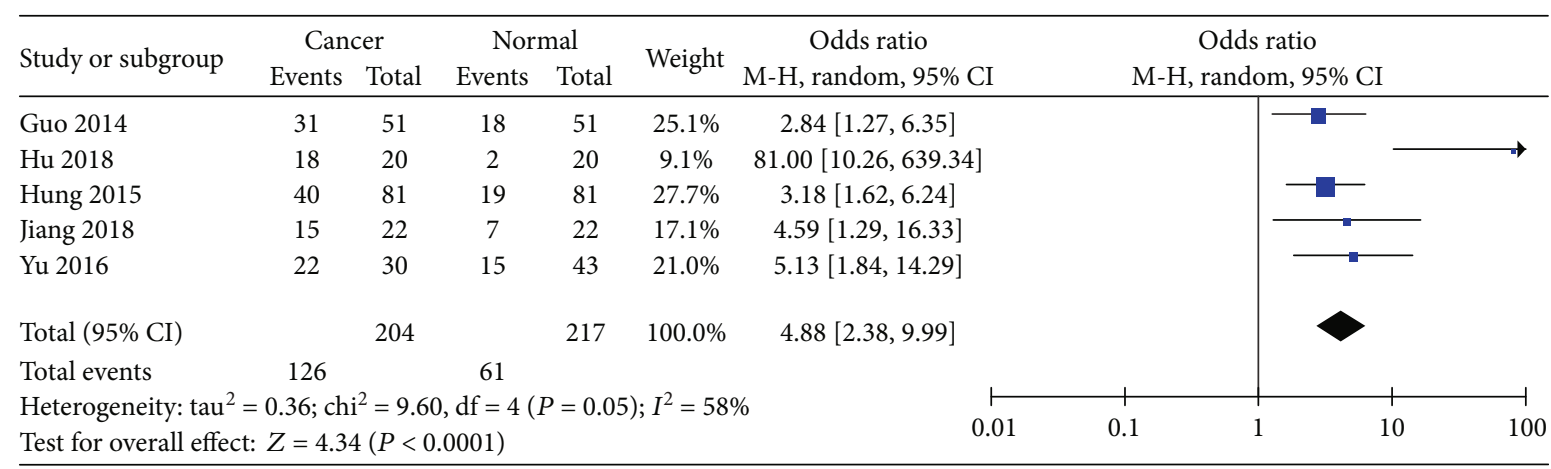

(a)

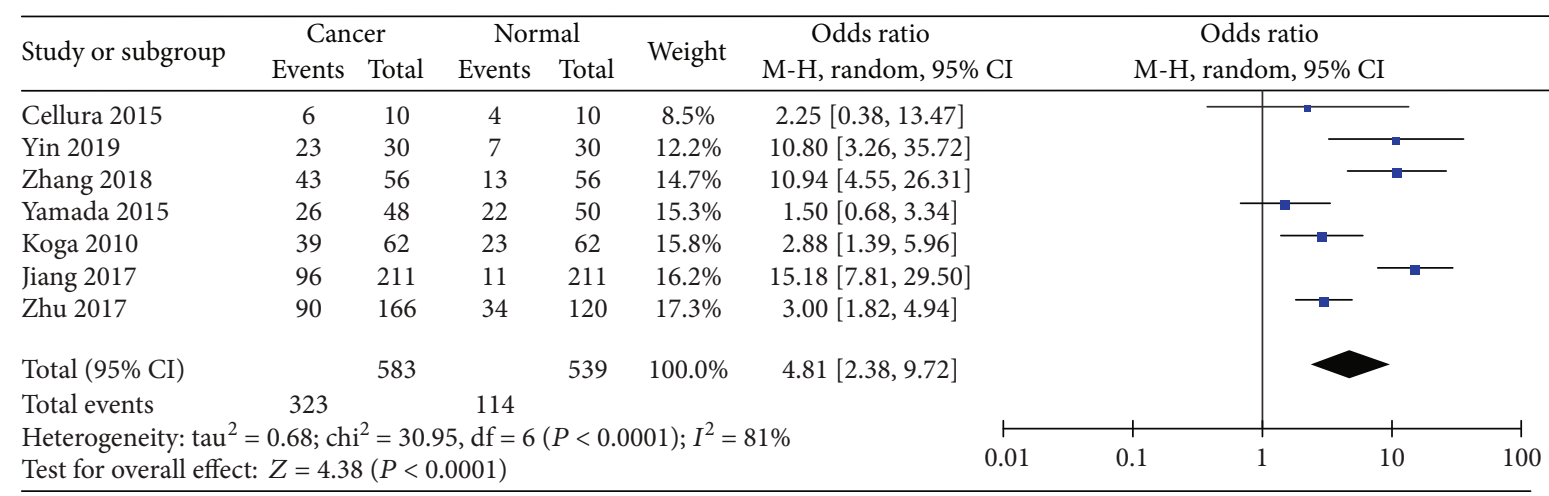

(b)

\begin{tabular}{|c|c|c|c|c|c|c|c|c|}
\hline \multirow{2}{*}{ Study or subgroup } & \multicolumn{2}{|c|}{ Cancer } & \multicolumn{2}{|c|}{ Normal } & \multirow{2}{*}{ Weight } & \multirow{2}{*}{$\begin{array}{c}\text { Odds ratio } \\
\text { M-H, random, 95\% CI }\end{array}$} & \multirow{2}{*}{$\begin{array}{c}\text { Odds ratio } \\
\mathrm{M}-\mathrm{H}, \text { random, 95\% CI }\end{array}$} & \\
\hline & Events & Total & Events & Total & & & & \\
\hline Cai 2016 & 28 & 60 & 6 & 8 & $9.2 \%$ & $0.29[0.05,1.56]$ & & \\
\hline Ibarrola-Villava 2015 & 28 & 45 & 17 & 45 & $11.3 \%$ & $2.71[1.16,6.36]$ & & \\
\hline Li 2018 & 26 & 42 & 16 & 42 & $11.3 \%$ & $2.64[1.09,6.37]$ & & \\
\hline Liu 2018 & 64 & 80 & 20 & 82 & $11.5 \%$ & $12.40[5.89,26.10]$ & & \\
\hline Peng 2018 (1) & 164 & 333 & 61 & 117 & $12.0 \%$ & $0.89[0.58,1.36]$ & & \\
\hline Peng 2018 (2) & 163 & 333 & 62 & 117 & $12.0 \%$ & $0.85[0.56,1.30]$ & & \\
\hline Wang 2016 & 16 & 90 & 74 & 90 & $11.5 \%$ & $0.05[0.02,0.10]$ & & \\
\hline Wang 2017 & 77 & 110 & 33 & 110 & $11.8 \%$ & $5.44[3.06,9.69]$ & $=$ & \\
\hline Zhu 2019 & 24 & 40 & 2 & 12 & $9.3 \%$ & $7.50[1.45,38.85]$ & & \\
\hline Total (95\% CI) & & 1133 & & 623 & $100.0 \%$ & $1.49[0.54,4.11]$ & & \\
\hline Total events & 590 & & 291 & & & & & \\
\hline $\begin{array}{l}\text { Heterogeneity: } \operatorname{tau}^{2}= \\
\text { Test for overall effect: }\end{array}$ & $\begin{array}{l}2.17 ; \mathrm{ch} \\
Z=0.7\end{array}$ & $\begin{array}{l}2=15 \\
(P=\end{array}$ & $1, \mathrm{df}=$ & $P<$ & $0001) ; 1$ & 0.01 & 0.1 & 100 \\
\hline
\end{tabular}

(c)

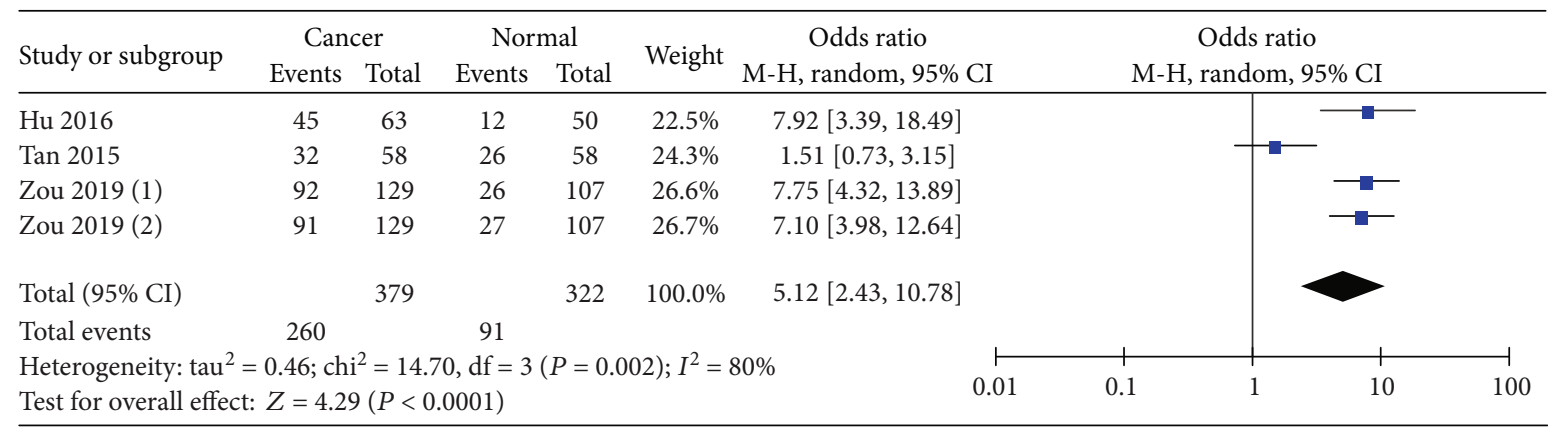

(d)

FIGURE 3: Forest plot of odds ratio (OR). (a) Comparison of the expression level of miR-19 between liver cancer and control. (b) Comparison of the expression level of miR-19 between colorectal cancer and control. (c) Comparison of the expression level of miR-19 between gastric cancer and control. (d) Comparison of the expression level of miR-19 between pancreatic cancer and control. 


\begin{tabular}{|c|c|c|c|c|c|c|c|c|c|}
\hline \multirow{3}{*}{$\begin{array}{l}\text { Study or subgroup } \\
\text { Yin } 2019\end{array}$} & \multicolumn{2}{|c|}{ Stages III-IV } & \multicolumn{2}{|c|}{ Stages I-II } & \multirow{3}{*}{$\begin{array}{c}\text { Weight } \\
5.2 \%\end{array}$} & \multirow{2}{*}{$\begin{array}{c}\text { Odds ratio } \\
\mathrm{M}-\mathrm{H} \text {, random, } 95 \% \mathrm{CI}\end{array}$} & \multirow{2}{*}{\multicolumn{2}{|c|}{$\begin{array}{c}\text { Odds ratio } \\
\mathrm{M}-\mathrm{H} \text {, random, } 95 \% \mathrm{CI}\end{array}$}} & \\
\hline & \multirow{2}{*}{$\frac{\text { Events }}{13}$} & \multirow{2}{*}{$\frac{\text { Total }}{19}$} & \multirow{2}{*}{$\frac{\text { Events }}{2}$} & \multirow{2}{*}{$\frac{\text { Total }}{11}$} & & & & & \\
\hline & & & & & & $9.75[1.59,59.70]$ & & & \\
\hline Guo 2014 & 25 & 34 & 6 & 17 & $6.7 \%$ & $5.09[1.45,17.83]$ & & & \\
\hline Zhu 2010 & 7 & 33 & 21 & 62 & $7.4 \%$ & $0.53[0.20,1.41]$ & & & \\
\hline Hung 2015 & 9 & 23 & 31 & 58 & $7.5 \%$ & $0.56[0.21,1.50]$ & & & \\
\hline Zhu 2018 & 92 & 106 & 67 & 74 & $7.5 \%$ & $0.69[0.26,1.79]$ & & & \\
\hline Wang 2016 & 14 & 42 & 31 & 48 & $7.7 \%$ & $0.27[0.11,0.66]$ & & & \\
\hline Huang-s2 2015 & 32 & 50 & 16 & 38 & $7.8 \%$ & $2.44[1.03,5.81]$ & & & \\
\hline Zhang 2015 & 18 & 67 & 44 & 63 & $8.0 \%$ & $0.16[0.07,0.34]$ & & & \\
\hline Jiang 2017 & 68 & 97 & 28 & 114 & $8.4 \%$ & $7.20[3.92,13.24]$ & & & \\
\hline Xu 2014 & 43 & 116 & 24 & 94 & $8.4 \%$ & $1.72[0.95,3.12]$ & & & \\
\hline Matsumura 2015 & 77 & 102 & 56 & 107 & $8.4 \%$ & $2.81[1.56,5.06]$ & & & \\
\hline Huang-s1 2015 & 27 & 90 & 45 & 120 & $8.4 \%$ & $0.71[0.40,1.28]$ & & & \\
\hline Huang 2015 & 37 & 127 & 28 & 148 & $8.5 \%$ & $1.76[1.00,3.09]$ & & & \\
\hline Total $(95 \% \mathrm{CI})$ & & 906 & & 954 & $100.0 \%$ & $1.28[0.68,2.41]$ & & & \\
\hline Total events & 462 & & 399 & & & & & & \\
\hline Heterogeneity: $\operatorname{tau}^{2}=$ & $\begin{array}{l}\mathrm{hi}^{2}=103 \\
76(P=0\end{array}$ & $\mathrm{df}=1$ & $<0.00001$ & $I^{2}=88 \%$ & & $\begin{array}{l}\longmapsto \\
0.01\end{array}$ & 0.1 & 10 & 100 \\
\hline Test for overall effect & $76(P=0$ & & & & & 0.01 & Stages III-IV & Stages I-II & 100 \\
\hline
\end{tabular}

FIGURE 4: Forest plot of odds ratio (OR). Association between miR-19 expression and tumor stage in overall gastrointestinal malignancy.

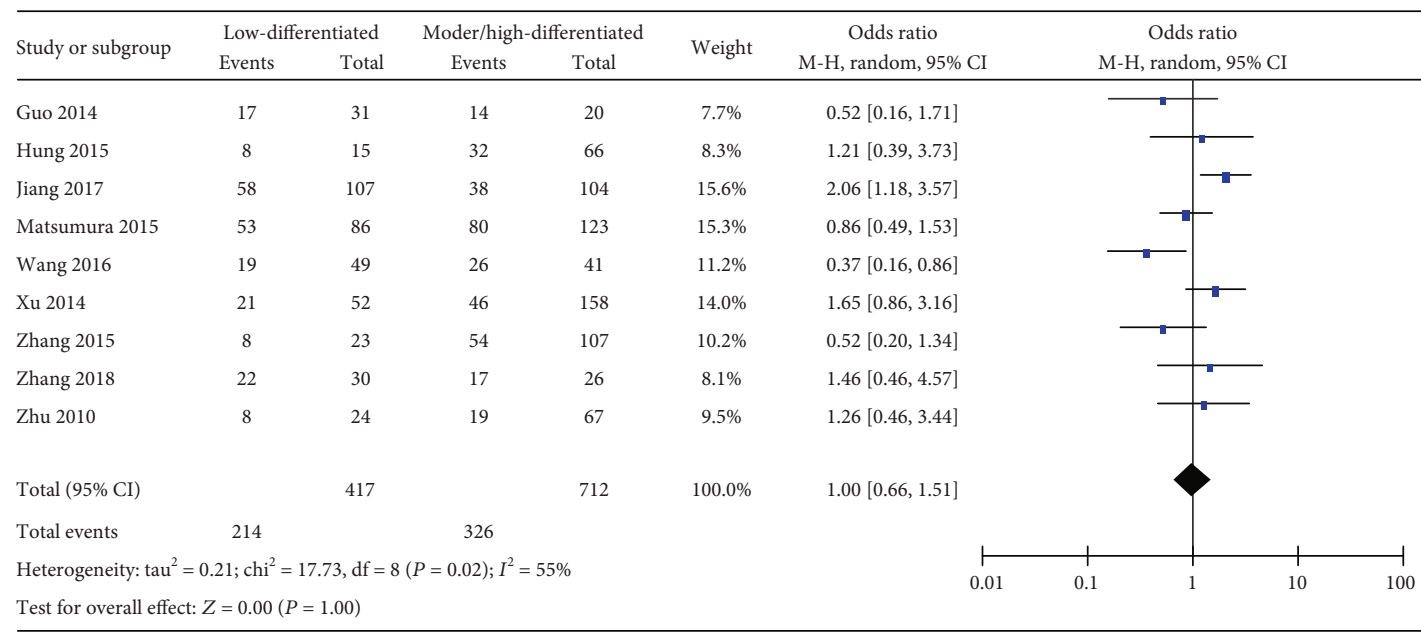

FIGURE 5: Forest plot of odds ratio (OR). Association between miR-19 expression and tumor differentiation degree in overall gastrointestinal malignancy.

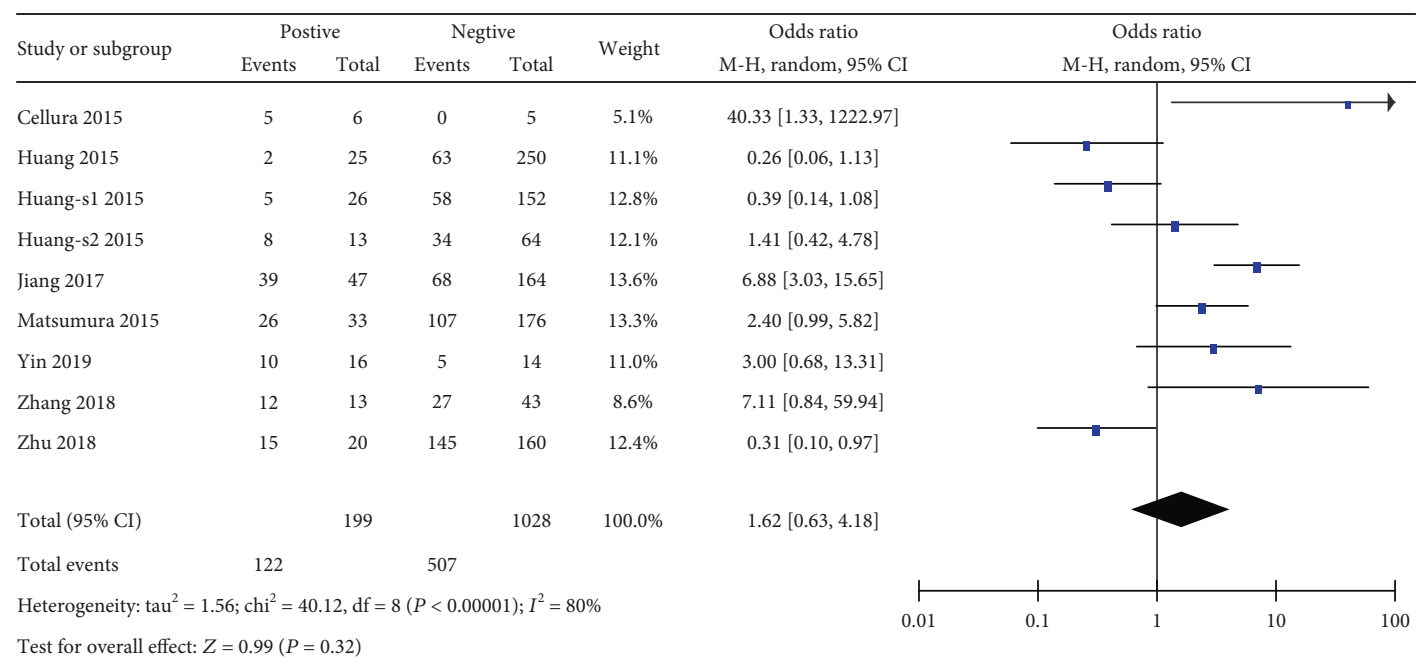

FIGURE 6: Forest plot of odds ratio (OR). Association between miR-19 expression and distant metastasis in overall gastrointestinal malignancy. 


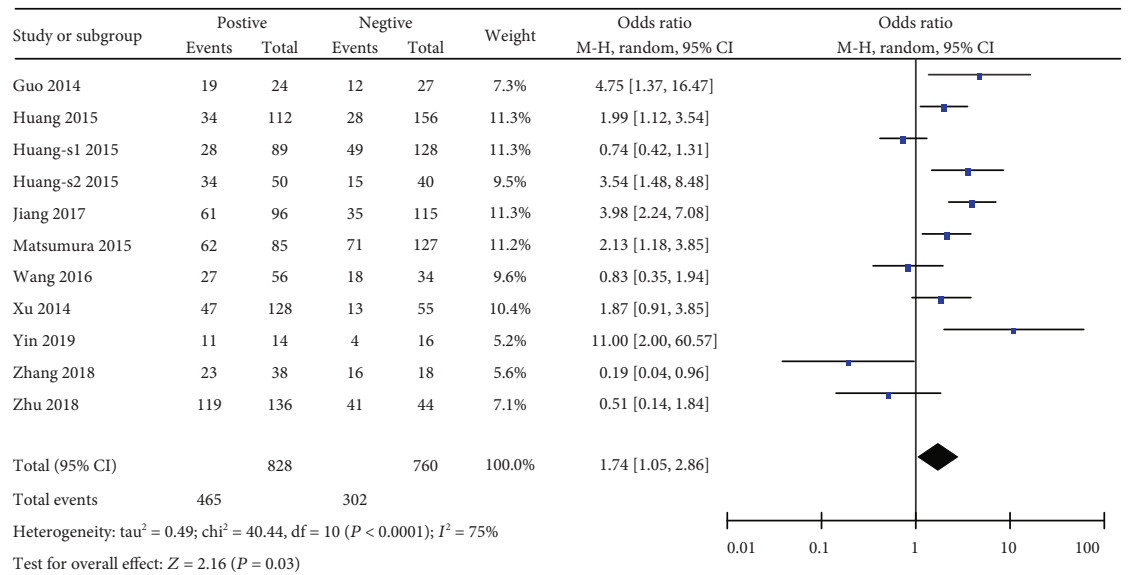

Figure 7: Forest plot of odds ratio (OR). Association between miR-19 expression and lymph node metastasis in overall gastrointestinal malignancy.

TABLE 3: Subgroup analyses were stratified on the basis of histology.

\begin{tabular}{|c|c|c|c|c|c|c|c|c|}
\hline & & Stage & & Grade & Lym & node metastasis & & nt metastasis \\
\hline \multirow{2}{*}{ Colorectal cancer } & $N$ & OR (95\% CI) & $N$ & OR (95\% CI) & $N$ & OR (95\% CI) & $N$ & OR (95\% CI) \\
\hline & 6 & $2.74(1.45,5.18)$ & 3 & $1.36(0.74,2.51)$ & 7 & $1.89(0.99,3.63)$ & 8 & $2.02(0.77,5.32)$ \\
\hline \multirow{2}{*}{ Gastric cancer } & $N$ & OR (95\% CI) & $N$ & OR (95\% CI) & $N$ & OR (95\% CI) & $N$ & OR (95\% CI) \\
\hline & 2 & $0.42(0.17,1.04)$ & 2 & $0.31(0.14,0.70)$ & 3 & $0.46(0.14,1.52)$ & 1 & $0.31(0.10,0.97)$ \\
\hline \multirow{2}{*}{ Esophagus cancer } & $N$ & OR (95\% CI) & $N$ & OR (95\% CI) & $N$ & OR (95\% CI) & $N$ & OR (95\% CI) \\
\hline & 1 & $1.72(0.95,3.12)$ & 1 & $1.65(0.86,3.16)$ & 1 & $1.87(0.91,3.85)$ & None & None \\
\hline \multirow{2}{*}{ Liver cancer } & $N$ & OR (95\% CI) & $N$ & OR (95\% CI) & $N$ & OR (95\% CI) & $N$ & OR (95\% CI) \\
\hline & 4 & $0.66(0.18,2.45)$ & 4 & $0.80(0.47,1.35)$ & 1 & $4.75(1.37,16.47)$ & None & None \\
\hline \multirow{2}{*}{ Pancreatic cancer } & $N$ & OR (95\% CI) & $N$ & OR (95\% CI) & $N$ & OR (95\% CI) & $N$ & OR (95\% CI) \\
\hline & None & None & None & None & None & None & None & None \\
\hline
\end{tabular}

Abbreviations: $N$ : study numbers.

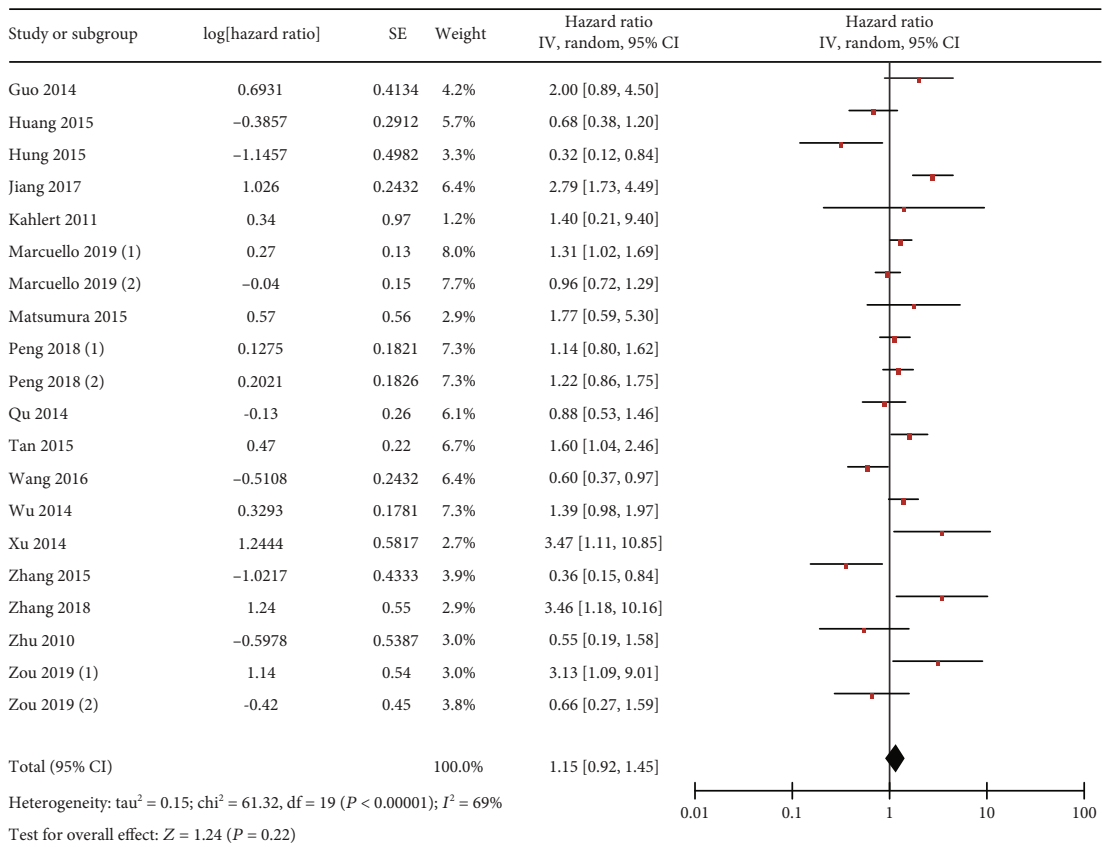

FIGURE 8: Forest plot of hazard ratio (HR). Association between miR-19 expression and the OS of overall gastrointestinal cancer patients. 


\begin{tabular}{lccccc}
\hline Study or subgroup & $\log [$ hazard ratio] & SE & Weight & $\begin{array}{c}\text { Hazard ratio } \\
\text { IV, random, 95\% CI }\end{array}$ \\
\hline Guo 2014 & 0.6931 & 0.4134 & $26.6 \%$ & $2.00[0.89,4.50]$ \\
Hung 2015 & -1.1457 & 0.4982 & $24.2 \%$ & $0.32[0.12,0.84]$ \\
Zhang 2015 & -1.0217 & 0.4333 & $26.1 \%$ & $0.36[0.15,0.84]$ \\
Zhu 2010 & -0.5978 & 0.5387 & $23.1 \%$ & $0.55[0.19,1.58]$ \\
Total (95\% CI) & & $100.0 \%$ & $0.61[0.25,1.49]$ & \\
Heterogeneity: taundom, 95\% CI
\end{tabular}

(a)

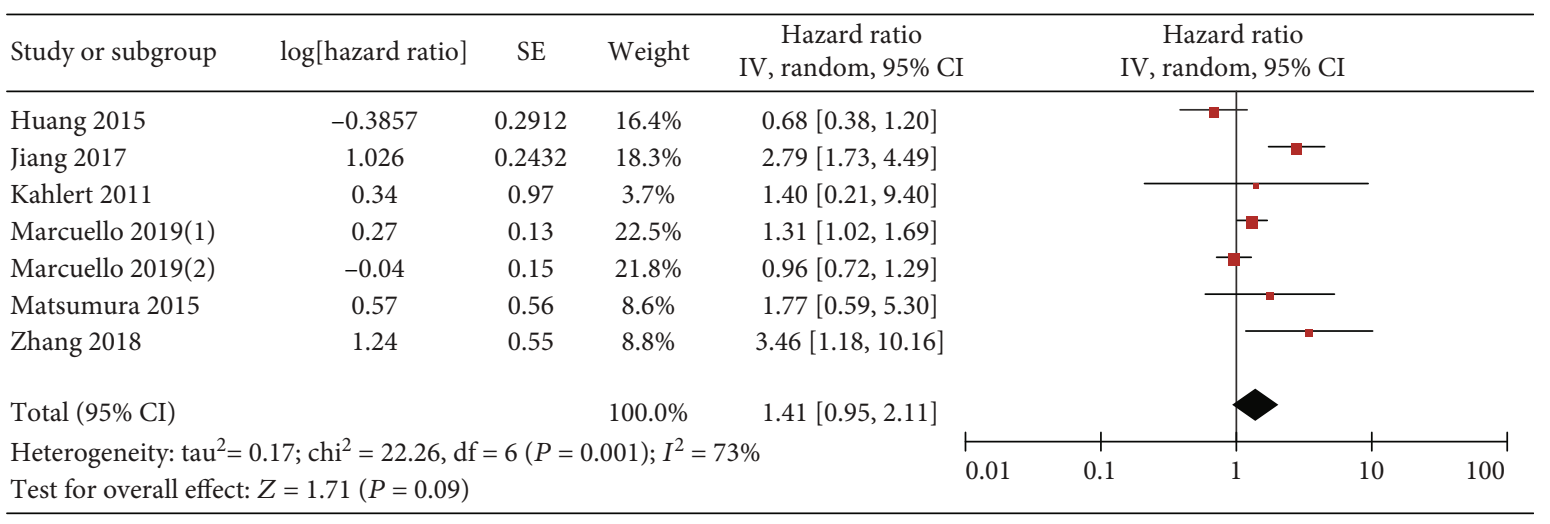

(b)

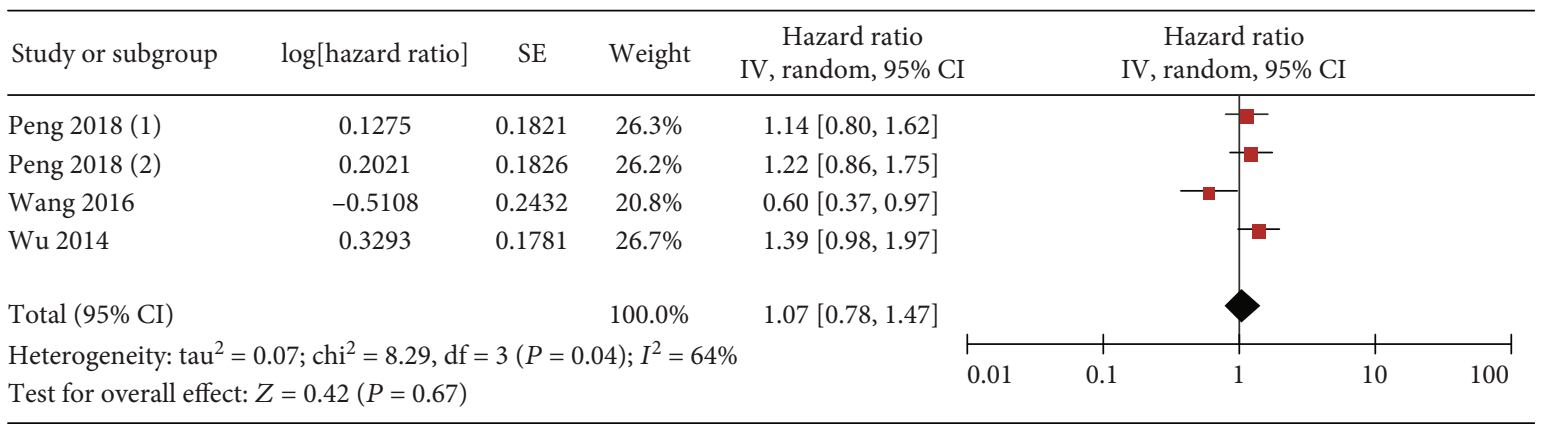

(c)

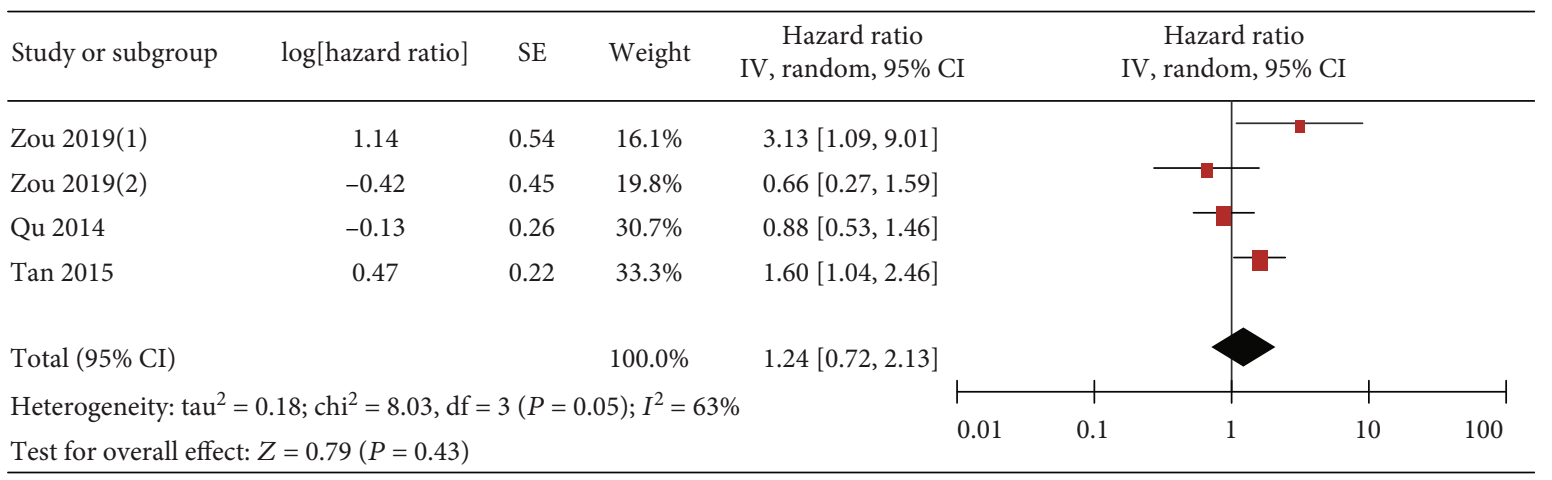

(d)

FIGURE 9: Forest plot of hazard ratio (HR). Association between miR-19 expression and the OS of liver cancer (a), colorectal cancer (b), gastric cancer (c), and pancreatic cancer (d) patients.

the clinicopathologic characteristics of patients with gastrointestinal malignancy. Unfortunately, there is no significant correlation between the miR-19 level and some clinical features, such as the tumor stage, differentiation degree, or distant metastasis of overall gastrointestinal cancers (Figures 4-6). Interestingly, we discovered that miR-19 levels were upregulated in lymph node metastasis-positive patients $(\mathrm{OR}=1.74,95 \% \mathrm{CI}=1.05-2.86)$ (Figure 7$)$. 


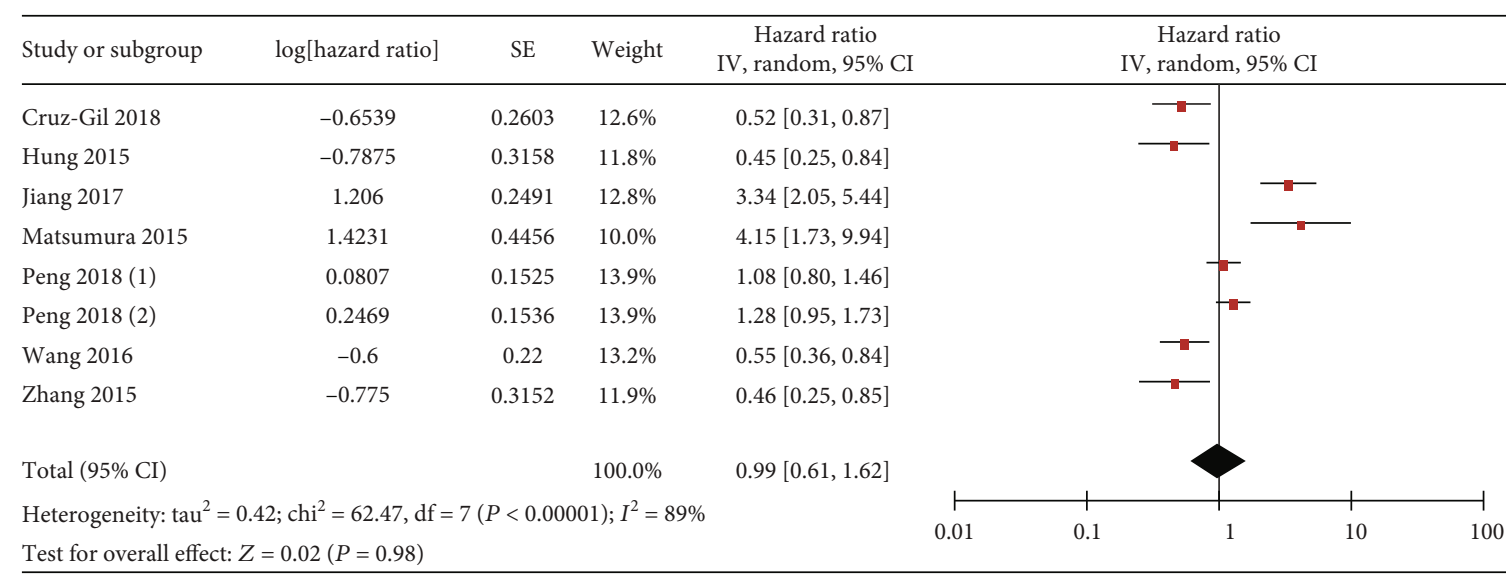

FIGURE 10: Forest plot of hazard ratio (HR). Association between miR-19 expression and the DFS of overall gastrointestinal cancer patients.

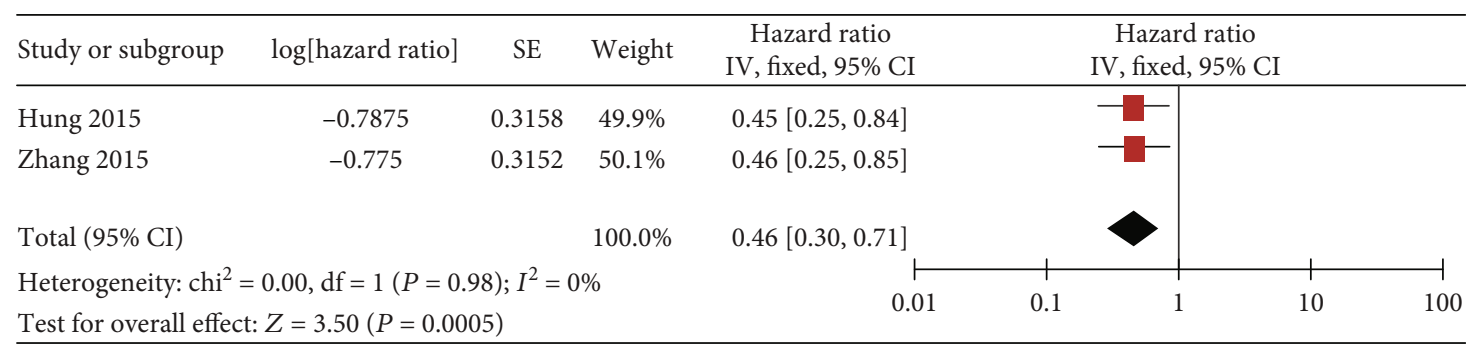

(a)

\begin{tabular}{lcccccc}
\hline Study or subgroup & $\log [$ hazard ratio] & SE & Weight & $\begin{array}{c}\text { Hazard ratio } \\
\text { IV, random, 95\% CI }\end{array}$ & \multicolumn{2}{c}{$\begin{array}{c}\text { Hazard ratio } \\
\text { IV, random, 95\% CI }\end{array}$} \\
\hline Cruz-Gil 2018 & -0.6539 & 0.2603 & $34.2 \%$ & $0.52[0.31,0.87]$ & \\
Jiang 2017 & 1.206 & 0.2491 & $34.4 \%$ & $3.34[2.05,5.44]$ \\
Matsumura 2015 & 1.4231 & 0.4456 & $31.4 \%$ & $4.15[1.73,9.94]$ \\
Total (95\% CI) & & & $100.0 \%$ & $1.89[0.48,7.47]$ & 1
\end{tabular}

(b)

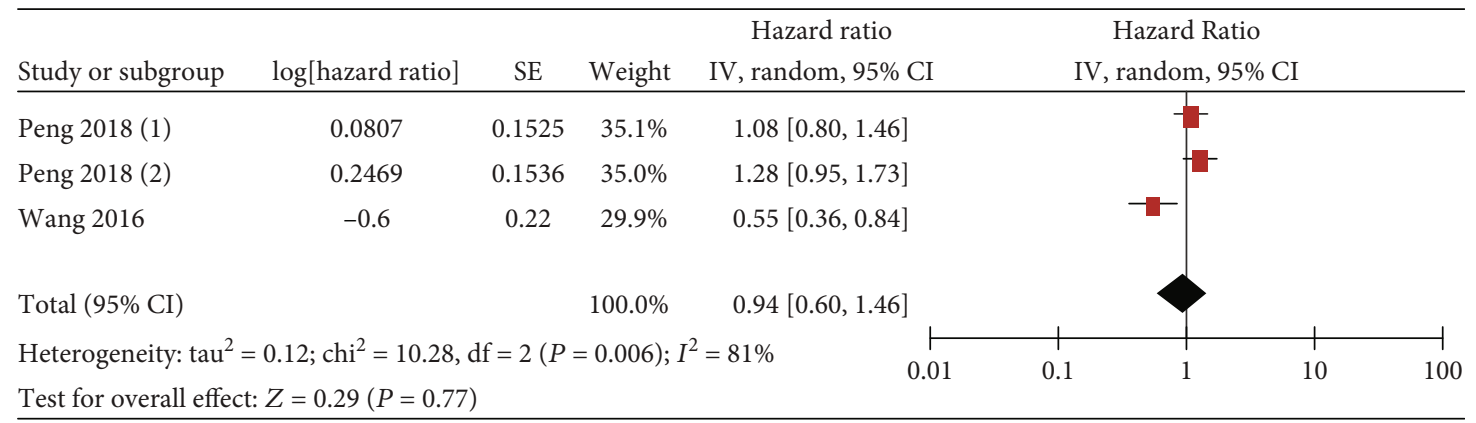

(c)

FIGURE 11: Forest plot of hazard ratio (HR). Association between miR-19 expression and the DFS of liver cancer (a) and colorectal cancer (b).

The results of subgroup analyses are displayed in Table 3. miR-19 levels in stages III-IV were higher than those in stage I-II colorectal cancer $(\mathrm{OR}=2.74,95 \% \mathrm{CI}=1.45-5.18)$. In addition, the miR-19 expression levels were lower in lowdifferentiated gastric tissues than those high-/moderate-differentiated ones $(\mathrm{OR}=0.31,95 \% \mathrm{CI}=0.14-0.70)$. There is no significant distinction in other analyses, and some analyses were short of studies ( 0 or 1 study), especially for esophagus and pancreatic cancers. Collectively, there are some relationship between miR-19 levels and clinicopathologic characteristics in gastrointestinal malignancy.

3.4. Influence of miR-19 on Clinical Outcome of Gastrointestinal Malignancy. Finally, the correlation between 
miR-19 and OS as well as disease-free survival (DFS) of gastrointestinal malignancy was investigated. Firstly, the analysis result showed that gastrointestinal cancer patients with low and high miR-19 expression showed comparable OS (Figure 8). Similar results were found in subgroup analyses for liver (Figure 9(a)), colorectal (Figure 9(b)), gastric (Figure 9(c)), and pancreatic (Figure 9(d)) cancers.

In addition, gastrointestinal cancer patients with low and high miR-19 expression showed comparable DFS as well (Figure 10). Subgroup analyses showed that the miR-19 level was positively associated with the DFS of liver cancer patients $(\mathrm{HR}=0.46,95 \% \mathrm{CI}=0.30-0.71) \quad$ (Figure 11(a)), but not colorectal and gastric cancer patients (Figures 11(b) and 11(c)). There was short of study analyzing the DFS of esophageal and pancreatic cancer patients ( 0 or 1 study).

3.5. Sensitivity and Bias Analysis. We conducted sensitivity analysis by removing a cohort one time. Results of metaanalyses were not altered greatly, suggesting the stability of these analyses. In addition, no significant publication biases existed according to the symmetric funnel plots (Supplement Figures. 1-7).

\section{Discussions}

In this study, an analysis of 37 studies revealed a potential role of miR-19 in the progression and prognosis of gastrointestinal cancers. At first, miR-19 levels in gastrointestinal cancers are significantly higher than those in controls. In addition, the association of miR-19 expression with clinical characteristics, such as the clinical stage, tumor differentiation degree, and lymph node and distant metastasis state, was described in subgroup analysis. At last, we depicted that liver cancer patients with higher miR-19 levels showed better DFS than those with low miR-19.

miR-19 expression levels in different gastrointestinal malignancies are inconsistent. For liver and colorectal cancers, most studies showed that miR-19 is overexpressed in cancer patients compared with normal controls. However, miR-19 expression in gastric and pancreatic cancers is controversy. For example, it has been illustrated that the miR19 levels were upregulated significantly in gastric cancer patients [19, 32], but another study [9] discovered that miR-19 levels were decreased in gastric tumors. In addition, the miR-19 level has been demonstrated to be upregulated in pancreatic cancer [18], but no difference between pancreatic cancer and control was observed in another study [31]. In this study, miR-19 levels in gastrointestinal malignancy were higher than those in the control generally. However, it is necessary to do much more work for pancreatic and esophagus cancers due to the limited number of included studies.

In the present study, significant correlation between miR19 levels and lymph node metastasis was observed in gastrointestinal malignancy, suggesting the role of miR-19 as a potential biomarker to diagnose patients with lymph node metastasis. Although the correlations between miR-19 and clinical stage, tumor differentiation degree, or distant metastasis state in the overall gastrointestinal malignancy were not significant, subgroup analysis has shown that miR-19 has diagnostic value in specific cancer types. In addition, no correlation between miR-19 and OS or DFS of overall gastrointestinal malignancy was observed, but the miR-19 level was positively correlated with the DFS of liver cancer patients as depicted in subgroup analyses, indicating that miR-19 shows its potential as a prognostic biomarker for liver cancer and would be beneficial for screening out high-risk liver cancer patients.

\section{Conclusions}

This study revealed the clinical significance of the miR-19 level in gastrointestinal malignancy. miR-19 could be a potential clinical biomarker for the progress and survival evaluation for gastrointestinal cancers and used as a new target for gastrointestinal cancer treatment.

\section{Conflicts of Interest}

The authors declared no conflicts of interest.

\section{Supplementary Materials}

Supplementary 1. Figure 1: funnel plots of publication bias in the meta-analysis as shown in Figure 2.

Supplementary 2. Figure 2: funnel plots of publication bias in the meta-analysis of miR-19 expression and tumor stage.

Supplementary 3. Figure 3: funnel plots of publication bias in the meta-analysis of miR-19 expression and tumor differentiation degree.

Supplementary 4. Figure 4: funnel plots of publication bias in the meta-analysis of miR-19 expression and lymph node metastasis.

Supplementary 5. Figure 5: funnel plots of publication bias in the meta-analysis of miR-19 expression and distant metastasis.

Supplementary 6. Figure 6: funnel plots of publication bias in the meta-analysis of miR-19 expression and OS as shown in Figure 8.

Supplementary 7. Figure 7: funnel plots of publication bias in the meta-analysis of miR-19 expression and DFS as shown in Figure 10.

\section{References}

[1] J. Ferlay, I. Soerjomataram, R. Dikshit et al., "Cancer incidence and mortality worldwide: sources, methods and major patterns in GLOBOCAN 2012," International Journal of Cancer, vol. 136, no. 5, pp. E359-E386, 2015.

[2] K. D. Crew and A. I. Neugut, "Epidemiology of gastric cancer," World Journal of Gastroenterology, vol. 12, no. 3, pp. 354-362, 2006.

[3] D. P. Bartel, "MicroRNAs," Cell, vol. 116, no. 2, pp. 281-297, 2004.

[4] R. Liu, X. Chen, Y. Du et al., "Serum microRNA expression profile as a biomarker in the diagnosis and prognosis of 
pancreatic cancer," Clinical Chemistry, vol. 58, no. 3, pp. 610618, 2012.

[5] C. Zhang, C. Wang, X. Chen et al., "Expression profile of microRNAs in serum: a fingerprint for esophageal squamous cell carcinoma," Clinical Chemistry, vol. 56, no. 12, pp. 1871$1879,2010$.

[6] X. Zhou, W. Zhu, H. Li et al., "Diagnostic value of a plasma microRNA signature in gastric cancer: a microRNA expression analysis," Scientific Reports, vol. 5, no. 1, article 11251, 2015.

[7] Z. B. Han, L. Zhong, M. J. Teng et al., "Identification of recurrence-related microRNAs in hepatocellular carcinoma following liver transplantation," Molecular Oncology, vol. 6, no. 4, pp. 445-457, 2012.

[8] M. D. Giráldez, J. J. Lozano, G. Ramírez et al., "Circulating microRNAs as biomarkers of colorectal cancer: results from a genome-wide profiling and validation study," Clinical Gastroenterology and Hepatology, vol. 11, no. 6, pp. 681-688.e3, 2013.

[9] H. Wang, M. Xiong, Y. Hu, Y. Sun, and Q. Ma, "MicroRNA19b inhibits proliferation of gastric cancer cells by targeting B-cell CLL/lymphoma 3," Oncology Reports, vol. 36, no. 4, pp. 2079-2086, 2016.

[10] Y. Bai, H. Lin, Z. Fang et al., "Plasma microRNA-19a as a potential biomarker for esophageal squamous cell carcinoma diagnosis and prognosis," Biomarkers in Medicine, vol. 11, no. 5, pp. 431-441, 2017.

[11] J. F. Tierney, L. A. Stewart, D. Ghersi, S. Burdett, and M. R. Sydes, "Practical methods for incorporating summary timeto-event data into meta-analysis," Trials, vol. 8, no. 1, 2007.

[12] L. Ma, H. Cai, J. Xu et al., "Integrated miRNA-risk genepathway pair network analysis provides prognostic biomarkers for gastric cancer," OncoTargets and Therapy, vol. 9, pp. 29752986, 2016.

[13] D. Cellura, K. Pickard, S. Quaratino et al., "miR-19-mediated inhibition of transglutaminase-2 leads to enhanced invasion and metastasis in colorectal cancer," Molecular Cancer Research, vol. 13, no. 7, pp. 1095-1105, 2015.

[14] S. Cruz-Gil, R. Sanchez-Martinez, M. G. de Cedron et al., "Targeting the lipid metabolic axis ACSL/SCD in colorectal cancer progression by therapeutic miRNAs: miR-19b-1 role," Journal of Lipid Research, vol. 59, no. 1, pp. 14-24, 2018.

[15] B. Hu, W. G. Tang, J. Fan, Y. Xu, and H. X. Sun, "Differentially expressed miRNAs in hepatocellular carcinoma cells under hypoxic conditions are associated with transcription and phosphorylation," Oncology Letters, vol. 15, no. 1, pp. 467-474, 2018.

[16] L. Huang, X. Wang, C. Wen et al., "Hsa-miR-19a is associated with lymph metastasis and mediates the TNF- $\alpha$ induced epithelial-to-mesenchymal transition in colorectal cancer," Scientific Reports, vol. 5, no. 1, article 13350, 2015.

[17] C. L. Hung, C. S. Yen, H. W. Tsai, Y. C. Su, and C. J. Yen, "Upregulation of microRNA-19b predicts good prognosis in patients with hepatocellular carcinoma presenting with vascular invasion or multifocal disease," BMC Cancer, vol. 15, no. 1, 2015.

[18] M. Hu, The functional role and underlying mechanisms of micro RNA-19b in necrotizing pancreatitis and pancreatic ductal ademocarcinoma, [Ph.D. thesis], Shandong University Dissertation for Doctoral Degree, 2016.

[19] M. Ibarrola-Villava, M. J. Llorca-Cardeñosa, N. Tarazona et al., "Deregulation ofARID1A,CDH1,cMETandPIK3CAand target-related microRNA expression in gastric cancer," Oncotarget, vol. 6, no. 29, pp. 26935-26945, 2015.

[20] T. Jiang, L. Ye, Z. Han et al., "miR-19b-3p promotes colon cancer proliferation and oxaliplatin-based chemoresistance by targeting SMAD4: validation by bioinformatics and experimental analyses," Journal of Experimental \& Clinical Cancer Research, vol. 36, no. 1, 2017.

[21] X. M. Jiang, X. N. Yu, T. T. Liu et al., "microRNA-19a-3p promotes tumor metastasis and chemoresistance through the PTEN/Akt pathway in hepatocellular carcinoma," Biomedicine \& Pharmacotherapy, vol. 105, pp. 1147-1154, 2018.

[22] C. Kahlert, F. Klupp, K. Brand et al., "Invasion front-specific expression and prognostic significance of microRNA in colorectal liver metastases," Cancer Science, vol. 102, no. 10, pp. 1799-1807, 2011.

[23] Y. Koga, M. Yasunaga, A. Takahashi et al., "MicroRNA expression profiling of exfoliated colonocytes isolated from feces for colorectal cancer screening," Cancer Prevention Research, vol. 3, no. 11, pp. 1435-1442, 2010.

[24] Y. Li, S. Lv, H. Ning et al., "Down-regulation of CASC2 contributes to cisplatin resistance in gastric cancer by sponging miR-19a," Biomedicine \& Pharmacotherapy, vol. 108, pp. 1775-1782, 2018.

[25] Y. Li, Z. Xu, B. Li et al., "Epigenetic silencing of miRNA-9 is correlated with promoter-proximal CpG island hypermethylation in gastric cancer in vitro and in vivo," International Journal of Oncology, vol. 45, no. 6, pp. 2576-2586, 2014.

[26] H. N. Liu, H. Wu, Y. J. Tseng et al., "Serum microRNA signatures and metabolomics have high diagnostic value in gastric cancer," BMC Cancer, vol. 18, no. 1, 2018.

[27] M. Marcuello, S. Duran-Sanchon, L. Moreno et al., “Analysis of a 6-miRNA signature in serum from colorectal cancer screening participants as non-invasive biomarkers for advanced adenoma and colorectal cancer detection," Cancers, vol. 11, no. 10, 2019.

[28] T. Matsumura, K. Sugimachi, H. Iinuma et al., "Exosomal microRNA in serum is a novel biomarker of recurrence in human colorectal cancer," British Journal of Cancer, vol. 113, no. 2, pp. 275-281, 2015.

[29] W. Peng, Y. N. Liu, S. Q. Zhu, W. Q. Li, and F. C. Guo, "The correlation of circulating pro-angiogenic miRNAs' expressions with disease risk, clinicopathological features, and survival profiles in gastric cancer," Cancer Medicine, vol. 7, no. 8, pp. 3773-3791, 2018.

[30] C. Qu, The correlation analysis between the tranditional Chinese medicine ZHENG and the expression of plasma prognostic mi RNA in non-resectable pancreatic cancer [Ph.D Thesis], Fudan University Dissertation for Master Degree, 2014.

[31] Y. Tan, H. Yin, H. Zhang et al., "Sp1-driven up-regulation of miR-19a decreases RHOB and promotes pancreatic cancer," Oncotarget, vol. 6, no. 19, pp. 17391-17403, 2015.

[32] N. Wang, L. Wang, Y. Yang, L. Gong, B. Xiao, and X. Liu, “A serum exosomal microRNA panel as a potential biomarker test for gastric cancer," Biochemical and Biophysical Research Communications, vol. 493, no. 3, pp. 1322-1328, 2017.

[33] Q. Wu, Z. Yang, Y. An et al., "miR-19a/b modulate the metastasis of gastric cancer cells by targeting the tumour suppressor MXD1," Cell Death \& Disease, vol. 5, article e1144, no. 3, 2014.

[34] X. L. Xu, Y. H. Jiang, J. G. Feng, D. Su, P. C. Chen, and W. M. Mao, "MicroRNA-17, microRNA-18a, and microRNA-19a are prognostic indicators in esophageal squamous cell carcinoma," 
The Annals of Thoracic Surgery, vol. 97, no. 3, pp. 1037-1045, 2014.

[35] A. Yamada, T. Horimatsu, Y. Okugawa et al., "Serum miR-21, miR-29a, and miR-125b are promising biomarkers for the early detection of colorectal neoplasia," Clinical Cancer Research, vol. 21, no. 18, pp. 4234-4242, 2015.

[36] Q. Yin, P. P. Wang, R. Peng, and H. Zhou, "miR-19a enhances cell proliferation, migration, and invasiveness through enhancing lymphangiogenesis by targeting thrombospondin1 in colorectal cancer," Biochemistry and Cell Biology, vol. 97, no. 6, pp. 731-739, 2019.

[37] G. Yu, X. Chen, S. Chen, W. Ye, K. Hou, and M. Liang, "miR19a, miR-122 and miR-223 are differentially regulated by hepatitis B virus X protein and involve in cell proliferation in hepatoma cells," Journal of Translational Medicine, vol. 14, no. 1 , 2016.

[38] J. L. Yuehu Guo, B. Wang, W. Zhao, and M. He, "miR-19 expression in hepatocellular carcinoma and its clinical significance," Chinese Journal of General Surgery, vol. 23, no. 9, pp. 1217-1221, 2014.

[39] J. Zhang, Z. Wang, X. Han et al., "Up-regulation of microRNA-19b is associated with metastasis and predicts poor prognosis in patients with colorectal cancer," International Journal of Clinical and Experimental Pathology, vol. 11, no. 8, pp. 3952-3960, 2018.

[40] Y. Zhang, X. Guo, Z. Li et al., "A systematic investigation based on microRNA-mediated gene regulatory network reveals that dysregulation of microRNA-19a/Cyclin D1 axis confers an oncogenic potential and a worse prognosis in human hepatocellular carcinoma," RNA Biology, vol. 12, no. 6, pp. 643-657, 2015.

[41] F. Zhu, Q. Wu, Z. Ni, C. Lei, T. Li, and Y. Shi, "miR-19a/b and $\mathrm{MeCP} 2$ repress reciprocally to regulate multidrug resistance in gastric cancer cells," International Journal of Molecular Medicine, vol. 42, no. 1, pp. 228-236, 2018.

[42] J.-J. Zhu, Experimental study on metastasis-related mir-185 and mir-19 in hepatocellular carcinoma initial experimental study on function of has-mir-19 [Ph.D Thesis], Soochow University Dissertation for Master Degree, 2010.

[43] M. Zhu, Z. Huang, D. Zhu et al., "A panel of microRNA signature in serum for colorectal cancer diagnosis," Oncotarget, vol. 8, no. 10, pp. 17081-17091, 2017.

[44] Y. Zhu, L. Li, D. Hou et al., "MicroRNA-19a regulates the proliferation, migration and invasion of human gastric cancer cells by targeting CUL5," Archives of Biochemistry and Biophysics, vol. 662, pp. 93-100, 2019.

[45] X. Zou, J. Wei, Z. Huang et al., "Identification of a six-miRNA panel in serum benefiting pancreatic cancer diagnosis," Cancer Medicine, vol. 8, no. 6, pp. 2810-2822, 2019. 